\title{
ICT and Economic Growth in East African Countries: A Panel Data Approach
}

\author{
Kedir Aman Deco* \\ Department of Economics, College of Business and Economics, Madda Walabu University, \\ Bale Robe, Ethiopia \\ Kemal Nure Kawo \\ Department of Statistics, College of Natural and Computational Science, Madda Walabu University, \\ Bale Robe, Ethiopia \\ Ahmed Hassen Dessiso \\ Department of Statistics, College of Natural and Computational Science, Madda Walabu University, \\ Bale Robe, Ethiopia
}

\begin{abstract}
This paper empirically investigates the impact of telecommunications infrastructure in East Africa. The researcher uses the International Telecommunication Union, UN and World Bank data and applies the instrumental variablegeneralized method of moments to a panel of 19 countries over the period 2000-2015. Whether telecommunication investment contributes or not to economic growth has been at the center of literature debate over time with varying empirical evidences for developed and developing nation. The effect of telecom market privatization has been controlled through independent panels. The results show that the telecom index composed of the Internet, mobile cellular and fixed line has contributed to economic growth. A one percentage point increase in this telecom index usage raises real per capita growth by 0.02 for the panel of whole countries. The result is more than this for countries that privatized their telecom sector and less for those that failed to privatize. Overall, the results suggest that the expansion of telecommunications infrastructure fosters economic growth in East Africa. With much room for potential growth enhancement of telecommunications infrastructure, policies to expand access to telecom services should be strongly encouraged by respective governments in general and privatization of telecommunication remained under government control in particular is desired.
\end{abstract}

DOI: 10.7176/JIEA/9-7-01

Publication date: December $31^{\text {st }} 2019$

\section{Introduction}

\subsection{Background of study}

The fundamental contribution of ICTs in facilitating and accelerating socio-economic development has undoubtedly gained acknowledgment across the world. The notion of Information and Communication Technology's (ICT's) role in economic performance of a given country is initially accounted by the American economist Robert Solow in which output per worker depends mainly on savings, population growth, and technological change (Solow R. , 1956). Growth can occur in through increased use of land, labour, capital and entrepreneurial resources by using better technology or management techniques and increasing productivity of existing resource use through rising labour and capital Productivity.

Since 1990, ICT investment has been considered as a proxy of technological progress and the telecommunication sector investment and services have been considered as the good proxy for ICT role in economic growth of a countries or a region. The indicators of telecommunication investments include fixed line subscribers per 100 inhabitants, mobile cellular subscribers per 100 inhabitants, internet users per 100 inhabitants, fixed and mobile broadband per 100 inhabitants, telecom revenues, taxes and employments as adapted by World bank, International telecommunications Union and others. Additionally, Network readiness Index has been developed by World Economic Forum.

A varying degree of ICT contribution to economic output in different stages of economic development and across Countries has been confirmed. For example, (Colecchia A. S., 2002) found that the contribution of ICT capital accumulation to output growth varied between 3\% and $9 \%$ during the 1990 s as compared to $2 \%$ and $5 \%$ during the 1970s and 1980s, respectively, for nine OECD countries. On the other hand, (Jorgenson, 2008) found a less important role of ICT on economic performance in the US in the post-2000 period as compared to the 1990s. A recent study, (Shahiduzzaman, 2014) found the evidence of less impressed role of ICT capital on economic growth and productivity in Australia in recent years as compared to the 1990s.

(Wong P. K., 2002) Found that the disparity in the intensity of ICT adoption among Asian countries is wider than disparities in their GDP per capita, and that Asia's share of global consumption of ICT goods, while gradually increasing over time, was consistently lower than its share in global production. 
During 1990s by using ICT in its economic performance, US government has been able to increase its economic productivity and inspire EU countries to use ICT sector. Similarly, by using ICT in their economic performance, countries such as Singapore, India, Taiwan, China, Korea, Malaysia, Ireland, Israel and Finland have been able to claim success stories that inspire a number of developing countries to invest in ICT and take its advantage (Hana, 2003). In the same manner a single country studies, (Kraemer K and Tallon P, 1999) on Ireland, (Oliner, 2000), and (Jorgenson D. W., 2000) on USA; (Dedrick J. and Kraemer K., 2001)'s study of Singapore; and (Joseph K.J., 2002) on India, showed that ICT contributed to economic growth.

Although micro-economic studies have found a positive correlation between IT investment and various measures of economic performance across firms in industrial countries, macro-economic studies have been less supportive tending to find no correlation, or even negative correlation between ITC investment and economy wide productivity (Brynjolfsson, 1996). At the country level, (Dedrick J and Kraemer K.L, 1994) found a significant relationship between IT investment and productivity growth with the data from 12 Asia Pacific countries. They showed that ITC investment is positive for developed countries but not significant for developing countries. (Pohjola M. J., 2002) Performed cross-country studies with the data from 39 and 42 countries covering the periods 1980-1995 and 1985-1999 respectively and the results confirmed (Kraemer K. \&., 2000)'s conclusion that IT plays a significant role in economic growth in developed countries but no substantiated role in developing countries. (Ngwenyama, 2006) Argued that studies have found a positive correlation between investment in ICTs and economic growth in developed countries, but evidence for developing countries is not as extensive.

The status of ICT development in African countries is appraised to be the lowest when compared to the rest of the world, and as well huge disparity is observed even within the countries of the continent. For most of developing economies particularly Africa, the contribution of ICT on economic growth may be insignificant or minim as result of most African's being at low status in ICT investment (Okogun, 2012). On the other hand WB and IMF reported as the African countries telecommunications sector has been doing great progress, more than other infrastructure sectors and its growth rate has been steadily improving during the last two decades, due to the liberalization process in which most African countries had to forgo in the 1990s, prodded by international institutions (Enowbi B. M., 2008).

The market structure of an ICT industry can affect its contribution to economic growth (van de Klundert, 1997) and (Aghion, 2005) According to these studies, this can happen, for instance, when the products of firms in the industry are imperfect substitutes and the firms have market power. Under such condition, the market structure can determine the R\&D effort in the industry. (Vahagn Jerbashiany, 2011), by analyzing channels through which Telecommunications contribute to economic growth, concluded when there are no barriers to entry both the direct and indirect network externalities add to growth. Otherwise, only direct network externalities matter.

However, right along with the increasing significance of the telecom sector, it is a field where the state interference is necessary based on the economic, social and political reasons arising from the features of the sector. This interference occurs in the ways that the state offers the service directly, and the state regulates and controls the service offered by the private sector. However, for the reason that the demand for the services offered by the state could not be met and the public sector could not adapt themselves to the improvements in technology, privatization practices became widespread in the early 1980's. Beginning in the 1980's and becoming widespread and an international phenomenon in the 1990's in the world, privatization has also become the tool for the reconstruction in the telecommunication sector. On the other hand, achievement of the privatization is dependent on the creating of a competitive private sector, instead of public monopoly. In this regard, it is necessary to adopt the competitive practices and to establish a level playing field in the sector (Gülşen, 2014). Telecommunications contribution can depend on the market structure of the telecommunications industry since the market structure can affect, for example, competitive pressure in the industry and therefore the incentives to innovate (Blundell, 1999) and (Vives, 2008).

In Africa, telecommunications contribute in a major way to the economic growth of the continent; there exist a significant and positive correlation between telecommunication infrastructures and regional growth in Africa, after controlling for a number of other factors (Enowbi B. M., 2008). He has showed that telecommunication is both statistically significant and positively correlated to regional economic growth in real GDP per capita growth in Africa. On the other hand (Ch.Nondo \& M.Kahsai, 2011) argued that government effectiveness is an important determinant for aggregate output and the incessant political upheavals in SSA countries have a detrimental effect on aggregate output.

World bank report indicated that, ICT has been a major driver of economic growth in Eastern Africa over the last decades, growing on average up to $40 \%$ in Revenues growing. Mobile service penetration in East Africa is as much as 5 times higher than Internet penetration, such that many applications that are available over the Internet in other parts of the world are available via mobile networks. This is true in spite of the limited computing and transmission capacity. Much of progress in the ICT sector in East Africa has been driven by larger corporations due to scale requirements that necessitate significant upfront capital expenditure. While this is laudable, the growth of a viable SME segment is fundamental to the long-term sustainability of the ICT sector and for addressing areas 
of unmet need that may not be lucrative enough for larger corporations and governments. The private sector, donors and governments have all instituted several initiatives to address the needs highlighted above, (World Bank, 2011). The studies regarding how ICT (telecommunication) is contributing to economic growth of the region is too few even when compared to other regions of Africa. This study tried to see what ICT development indicators looks like in the region, how these ICT developments are contributing to the economic growth of countries in the region over time and whether market structure of the telecom sector can greatly affect the economy differently or not.

\subsection{Statement of problem}

The fundamental contribution of ICTs in facilitating and accelerating economic growth has undoubtedly gained acknowledgment across the world. ICT contributes directly or indirectly to economic growth in various ways. The effects of telecommunication investment lead to growth by increasing the demand for goods and services used in their production and the economic return on these investments are far greater than the return from the investment alone, because there is a direct and an indirect effect on the production justifying greater multiplied effect on GDP (Canning.D, 1999). Telecommunication services increase the productivity of the economies in general by facilitating the information flow and by enhancing the communication between buyers and sellers, rural and urban areas and within the industrial sector. Both the fixed costs of acquiring information and the variable costs of participation in the market are lowered by the improvement of the ICT sector, as argued by (Norton S. W., 1992). When a telecommunication infrastructure exists, in equilibrium, idle resources are lower and markets are more efficient than when there is no telecom infrastructure, or no equilibrium, (Nandi.B, 2003).

Additionally, telecommunication sectors are creating high paying jobs, the revenues of telecommunications operators has the significant influence over the GDP and paying high taxation revenue towards governments. Regardless of such contributions there is no agreement among researchers on conditions, time and countries in which the impact of telecommunications on economic growth has greater impact. Different Studies have shown varying degree of ICT contribution to Economic growth. (Colecchia A. S., 2002) And (Jorgenson, 2008) have showed varying degree of ICT contribution to Economic growth over time. Studies have also showed difference in ICT contribution to Economic growth among developed countries (Colecchia A. S., 2002), comparing US with EU, among developed and developing countries (Dewan, 2000) and among developing countries themselves (Wong P. K., 2002).

Others studies have indicated, the performance and development of the telecommunications sector are related to the structure of the industry (Oniki, 1994), (Yoon, 1999), (Lien, 2001), (Nandi.B, 2003) and others. Some of east African Countries like Kenya, Sudan and Tanzania follows the neo-liberal doctrine of ICT policies, while others like Ethiopia has emerged to follow developmental state ideology similar with East Asian countries paradigm of development. More over countries such as Comoros, Djibouti, Eritrea, and Ethiopia retain major restrictions on foreign telecommunication investment in operators.

Related studies may be categorized as African and country level. At Africa level, (Enowbi B. M., 2008) using panel data with dynamic fixed effect $1984-2005$ to see the effects of telecommunications on the economic growth in African countries and concluded telecommunications contribute in a major way to the economic growth of the continent which showed that telecommunication is both statistically significant and positively correlated to regional economic growth in real GDP per capita growth. Nondo and Kahsai studied the role of government effectiveness, institutional and political factors in aggregate output and telecommunications penetration in SSA countries, aggregate output and telephone penetration rates using simultaneous growth equilibrium model and indicated that government effectiveness is an important determinant for aggregate output (Ch.Nondo \& M.Kahsai, 2011).

Others Country level studies focused mainly on ICT contribution to national economic growth and comparative with regard to ICT contribution to economic growth and political policy difference in Eastern Africa (Matambalya, 2001), (Yasin, 2012), (Ncube, 2013) and (Diriba, 2015).

Thus, this study is different from the previous studies as it intended to examine dynamic panel data analysis on ICT impact on economic growth in East African by including many telecommunications investment indicators than previous studies. The study is also accounts for telecom market difference using two separate panels for those privatized telecom sector and not privatized to control the effect of privatization and government control of the market so that it is possible to see whether market difference can affect the telecommunications impact on economic growth. Therefore, by including, telecommunication market (privatization) and other growth determinant economic variables, this study will endeavor to question to what extent telecommunication services are contributing to the Economic growth of East African Countries and can a difference in ICT market make significant differences in contributing to economic growth?

\subsection{Objectives of the study}

The general objective of this research is to analyze the effect of penetration of different types of telecom services 
on the economic growth of East Africa Countries, taking into account the market structures of their telecom sectors, whereas the specific objectives include:

$\$$ To show the direct impact of telecommunication sector on economic growth of these countries.

* To see whether difference in ICT market have significant effect on their contribution to economic growth.

* To show whether ICT markets (liberalization) has significant difference in contributing to Economic growth.

+ To put forth some policy implications and further studies.

\subsection{Significance of study}

ICT and Economic growth is become researchers interest since 1980. They found different results for different countries and no clear cut findings still exist. As such, it requires a thorough study in order to shed light on ICT impact and contributions to obtain a better understanding of the almost universal efforts by all countries to invest in ICT in order to benefit from it and the result obtained in investing and using IC for Africa's in general and East Africans in particular, long-term economic growth is a challenge to the governments of the region. Their ICT utilization needs to improve significantly if the region is to effectively address productive capacity and reduce transaction cost of the firms and peoples to an acceptable level. The challenge revolves around ways to encourage economic growth in view of the Containing ICT investment and market gap in the countries and identifying those factors that inhibit ICT investment. Hence, ICT impact has become the most sought for developing countries to fill their economic growth gap. Appropriate policies can then formulate and implemented to reduce those negative factors and strengthen the positive ones. Besides, this paper will be used for academician and other researcher as literature for those prevailing economic arena.

\section{Data and Methodology}

\subsection{Data structure and set}

The researcher was used the Panel type of economic data set. Using Panel data have many advantages over both cross-sectional and time series data sets. The availability of repeated observations on the same units allows economists to specify and estimate more complicated and more realistic models than a single cross-section or a single time series would do (Wooldridge, 2003). It also allows identification of certain parameters or questions, without the need to make restrictive assumptions. Because panel data sets are typically larger than cross-sectional or time series data sets, and explanatory variables vary over two dimensions (individuals and time) rather than one, estimators based on panel data are quite often more accurate than from other sources. Even with identical sample sizes, the use of a panel data set will often yield more efficient estimators than a series of independent crosssections (where different units are sampled in each period). If one is interested in changes from one period to another, a panel will yield more efficient estimators than a series of cross-sections. The results of Nijman and Verbeek analysis indicate that when exogenous variables are included in the model and if one is interested in the parameters which measure the effects of these variables, a panel data set will typically yield more efficient estimators than a series of cross-sections with the same number of observations (Verbeek, 2004).

The availability of panel data also reduces identification problems which involve identification in the presence of endogenous regressors or measurement error, robustness to omitted variables and the identification of individual dynamics. Other advantage of panel data is that in many cases panel data will provide internal instruments for regressors that are endogenous or subject to measurement error.

However, panel data approach has some disadvantage in practical nature. Because we repeatedly observe the same units, it is usually no longer appropriate to assume that different observations are independent which may complicate the analysis, particularly in nonlinear and dynamic models. Furthermore, panel data sets very often suffer from missing observations.

Taking into account the many advantages of panel data with its few disadvantages the research tried to utilize the panel data approach of economic data types.

\subsection{Data types and source}

Secondary data sources have been used in this study. The balanced panel consists of annual data for telecommunications development indicators ${ }^{1}$ has been obtained from International telecommunication Union (ITU), while data on the growth rate of real GDP per capita, imports and exports, real gross domestic product, investment, government expenditure for selected East African countries ${ }^{2}$ for the period 2000-2016 has been obtained from UN data base. Data on population growth rate and Countries sectoral privatization was adapted from World Bank data base. Data for all variables are measured in terms of internationally accepted units by

\footnotetext{
${ }^{1}$ fixed lines per 100 inhabitants, Mobile subscribers per 100 inhabitants, Internet users per 100 inhabitants and number of broadband internet available

${ }^{2}$ (Botswana, Burundi, Comoros, Djibouti, Eritrea, Ethiopia, Kenya, Madagascar, Malawi, Mauritius, Mozambique, Rwanda, Seychelles, Somalia, Sudan, Tanzania, Uganda, Zambia, Zimbabwe).
} 
organizations such as World Bank, IMF and World Economic Forum.

\subsection{Model specification}

Based on different empirical literature review, there is no general agreements as to which variables have to be included to determine the growth together with telecommunication indexes, however most literatures follow the neoclassical growth model of convergence. As one of specific objective, the basic one is to see the impact of ICT on economic growth; the researcher specifies the following panel dynamic econometric model following, (Barro, 1991)'s, (Levine, 1992) and then extended by (Anusua Datta \& Sumit Agarwal, 2004), (Ficawoyi, 2016) and others

The general form of the model to be estimated has the following form:

$$
\begin{aligned}
& \text { Growth }_{i, t}=\alpha_{i}+\phi_{t}+\beta_{1} \text { Growth }_{i, t-1}+\beta_{2} \text { RGDPPC }_{i . t-1}+\beta_{3} \text { Gov }_{i t}+\beta_{4} \text { Inv }_{i t}+\beta_{6} \text { Open }_{i t}+ \\
& \beta_{7} \text { Pop }_{i t}+\beta_{8} \mathrm{Tel}_{i t}+\varepsilon_{i t} \\
& \text { Growth }_{P, t}=\alpha_{P}+\phi_{t}+\beta_{1} \text { Growth }_{P, t-1}+\beta_{2} \text { RGDPPC }_{P . t-1}+\beta_{3} \text { Gov }_{P t}+\beta_{4} \text { Inv }_{P t}+\beta_{6} \text { Open }_{P t}+ \\
& \beta_{7} \text { Pop }_{P t}+\beta_{8} \mathrm{Tel}_{P t}+\varepsilon_{P t} \\
& \text { Growth }_{m, t}=\alpha_{i}+\phi_{t}+\beta_{1} \text { Growth }_{m, t-1}+\beta_{2} \text { RGDPPC }_{m . t-1}+\beta_{3} \text { Gov }_{m t}+\beta_{4} \text { Inv }_{m t}+\beta_{6} \text { Open }_{m t}+ \\
& \beta_{7} \mathrm{Pop}_{m t}+\beta_{8} \mathrm{Tel}_{m t}+\varepsilon_{m}
\end{aligned}
$$

Where, $\mathrm{i}$ indexes whole countries in the sample, $\mathrm{p}$ indexes panels of countries those privatized their telecom sector, $\mathrm{m}$ indexes countries those privatized their telecom sector; $\mathrm{t}$ indexes time, $\alpha, \theta$, and $\varepsilon$ are country-specific and timespecific parameters, and an error term, respectively.

Growth $_{i, t}=$ the annual growth rate of the real GDP per capita which is dependent Variable of the model.

Growth $_{i, t-1}=$ is the lagged of the annual growth rate of the real GDP per capita which captures the short-run autoregressive behavior of the dependent Variable. This is assumed because the Dynamic model (GMM) uses the lag of dependent variable by default.

$R G D P P C_{i . t-1}=$ is real GDP per capita, which measures the initial economic conditions and accounts for convergence in the growth rate. The convergence hypothesis according to neoclassical growth theory suggests that due to diminishing returns to capita, the growth rate of a country is inversely proportional to its initial level of income; the higher level of past GDP, the lower the subsequent growth.

$G o v_{i t}=$ Share of government expenditures as percentage of GDP and expected to have a positive or negative sign as there exists a non-monotonic relationship between growth and government size (Bajo-Rubio, 2000)

$I n v_{i t}=$ Is fixed share of investment in GDP and expected sign is positive

$\mathrm{Open}_{i t}=$ measures the extent to which the country is integrated into the global economy. It is measured as the share of total exports and imports for each country. Trade openness is expected to have a positive sign (Datta and Agarwal 2004). (Ficawoyi, 2016)

$P o p_{i t}=$ is the rate of growth of population and the expected sign for the population growth variable is negative, as a lower population growth relates to higher per capita GDP.

$T e l_{i t}=$ is the telecommunication indicator which is an index of growth rate of fixed lines per 100 inhabitants, Mobile subscribers per 100 inhabitants, Internet users per 100 inhabitants. It includes more telecom indexes than other previous studies based ICT indicators adapted by World Bank and others. All of these indicators were expected to have positive effect on growth, so is there index. The telecommunication index id constructed as follows:

$$
\text { TelecomomIndex }=1 / 3(\text { Mob.subscribers })+1 / 3(\text { FL.sunscribers })+1 / 3(\text { Inter.subscribers })
$$

Where, Mob subscribers is mobile cellular subscribers per 100 in habitants, FL subscriber is fixed line subscribers per 100 inhabitants and Inter subscriber is internet users per 100 inhabitants. As there are no previously assigned weights for these telecom investment indicators, the researcher assigned equal value for three of them.

Equation two and three is included to see the effect of privatization on telecom indicators development and then economy through the sector performances. As privatization of the telecommunication affects the sector itself and through the sector economic growth is affected. The Consideration for market structure of telecom (whether 
privatized or not ) is the fact that there were many studies which showed the significance differences in performances of telecom sectors as a results of their difference in industry in which they operate. (Nandi.B, 2003); (Lien, 2001); Oniki, Oum, Stevenson, \& Xhang, (1994), Yoon, (1999).

\subsubsection{Dynamic panel data (dpd) model}

In the context of panel data, we usually must deal with unobserved heterogeneity by applying the within (demeaning) transformation, as in one-way fixed effects models, or by taking first differences if the second dimension of the panel is a proper time series. A serious difficulty arises with the one-way fixed effects model particularly if $\mathrm{T}$ is smaller than $\mathrm{N}$, Baum (2013). The mean of the lagged dependent variable contains observations 0 through $(\mathrm{T}-1)$ on dependent variable, and the mean error which is being conceptually subtracted from each error term. The resulting correlation creates a bias in the estimate of the coefficient of the lagged dependent variable which is not mitigated by increasing $\mathrm{N}$, the number of individual units. The demeaning operation creates a regressor which cannot be distributed independently of the error term. If the regressors are correlated with the lagged dependent variable to some degree, their coefficients may be seriously biased as well. This bias is not caused by an auto correlated error process; the bias arises even if the error process is i.i.d. If the error process is auto correlated, the problem is even more severe given the difficulty of deriving a consistent estimate of the AR parameters in that context.

The same problem affects the random effects model. The ui error component enters every value of dependent variable, by assumption, so that the lagged dependent variable cannot be independent of the composite error process.

The paper considers the alternative model which is the DPD (Dynamic Panel Data). DPD approach is usually considered the work of Arellano and Bond. A key aspect of the Arellano and Bond strategy is the assumption that the necessary instruments are internal: that is, based on lagged values of the instrumented variable(s). The model allows the inclusion of external instruments as well. The Arellano and Bond approach, and its extension to the System GMM context, is an estimator designed for situations with: small T, large N panels: few time periods and many individual units, a linear functional relationship, one left-hand variable that is dynamic, depending on its own past realizations, right-hand variables that are not strictly exogenous: correlated with past and possibly current realizations of the error, fixed individual effects, implying unobserved heterogeneity, heteroscedasticity and autocorrelation within individual units' errors, but not across them.

The Arellano-Bond estimator sets up a generalized method of moments (GMM), which the model specified as a system of equations, one per time period, where the instruments applicable to each equation differ and assume endogeneity presence only involving the lagged dependent variable. It also is important to evaluate the SarganHansen test results when they are applied.

\subsection{Method of estimation and procedures}

\subsubsection{IV-GMM}

As confirmed by many literatures including more recent, there is a potential endogeneity issue between economic growth and technological progress confirming there is bidirectional causality between the two variables (Ficawoyi, 2016). With presence of a lagged dependent variable and autocorrelation in the error term, measurement errors in the regressors, and simultaneity or endogeneity of regressors, we can no longer argue that the OLS estimator is unbiased or consistent, and need to consider alternative estimators. Considering this problem the researcher used GMM for estimation which is expected to tackle such problems following Schaffer's (2010) and Adonsou et.al (2016). IV-GMM implements the instrumental variable/GMM estimation of the fixed-effects and first-differences panel data models with endogenous repressors. The method utilizes IV/2SLS but when compared to the standard IV/2SLS estimator, IV-GMM requires robust variance covariance estimation (Baum, 2003). A method of moments approach can unify the estimators and eliminate the disadvantages of reduced sample sizes. The GMM estimators are known to be consistent, asymptotically normal, and efficient in the class of all estimators that do not use any extra information aside from that contained in the moment conditions. The Sargan test of overidentifying is also checked for the model validity.

\subsection{Method of estimation and procedures}

\subsubsection{Instrumental variable-Generalized methods of moments}

As confirmed by many literatures including more recent, there is a potential endogeneity issue between economic growth and technological progress confirming there is bidirectional causality between the two variables (Adonsou, 2016). With presence of a lagged dependent variable and autocorrelation in the error term, measurement errors in the regressors, and simultaneity or endogeneity of regressors, we can no longer argue that the OLS estimator is unbiased or consistent, and need to consider alternative estimators. Considering this problem this paper used GMM for estimation which is expected to tackle such problems following (Baum, 2003) and (Adonsou, 2016). IV-GMM implements the instrumental variable/GMM estimation of the fixedeffects and first-differences panel data models with endogenous repressors. The method utilizes IV/2SLS but when compared to the standard IV/2SLS estimator, 
IV-GMM requires robust variance covariance estimation (Baum, 2003). A method of moments approach can unify the estimators and eliminate the disadvantages of reduced sample sizes. The GMM estimators are known to be consistent, asymptotically normal, and efficient in the class of all estimators that do not use any extra information aside from that contained in the moment conditions. The great advantages of the generalized method of moments are that; it does not require distributional assumptions such as normality, it can allow for heteroscedasticity of unknown form and it can estimate parameters even if the model cannot be solved analytically from the first order conditions.

Considering nature of data and sample the paper used the difference GMM approach that deals with inherent endogeneity by transforming the data to remove the fixed effects. The one disadvantage of the difference GMM is that it magnifies gaps in unbalanced panels. The data used in this research is strongly balanced, so that difference GMM can be applied. As the paper does not use the first differenced variables for which lagged level instruments are poor instruments, using the system GMM developed by Arellano and Bover (1995) and Blundell and Bond (1998) to tackle this problem is not mandatory because this estimator imposes additional restrictions on the initial conditions of the process generating. One step GMM is used here because two step GMM step standard errors were biased downwards and need additional correction procedures even though it is more asymptotically efficient. The two step need more observations per country in the level equation, make autoregressive coefficient is much large.

\subsubsection{Panel unit root test}

In order to investigate the possibility of panel Cointegration, it is first necessary to determine the existence of unit roots in the data series. For this study I have chosen the Im, Pesaran and Shin (IPS, hereafter), which is based on the well-known Dickey-Fuller procedure.

IPS proposed a test for the presence of unit roots in panels that combines information from the time series dimension with that from the cross section dimension, such that fewer time observations are required for the test to have power. Since the IPS test has been found to have superior test power by researchers in economics to analyze long-run relationships in panel data, we will also employ this procedure in this study. IPS begins by specifying a separate ADF regression for each cross-section with individual effects and no time trend:

$$
\Delta y_{i t}=\alpha_{i}+\rho_{i} y_{i, t-1}+\sum_{j=1}^{p_{i}} \beta_{i j} \Delta y_{i, t-j}+\varepsilon_{i t}
$$

Where $\mathrm{i}=1 \ldots N$ and $t=1 \ldots T$

IPS use separate unit root tests for the $N$ cross-section units. Their test is based on the Augmented Dickey-fuller (ADF) statistics averaged across groups. After estimating the separate ADF regressions, the average of the $t$ statistics for $\mathrm{p}_{1}$ from the individual ADF regressions,

$$
\begin{aligned}
\mathrm{t}_{\mathrm{iT}_{\mathrm{i}}}\left(\mathrm{p}_{\mathrm{i}}\right): & \\
\bar{t}_{N T} & =\frac{1}{N} \sum_{i=1}^{N} t_{i T}\left(p_{i} \beta_{i}\right)
\end{aligned}
$$

The $t$-bar is then standardized and it is shown that the standardized $t$-bar statistic converges to the standard normal distribution as $\mathrm{N}$ and $\mathrm{T} \rightarrow \infty$. IPS (1997) showed that $t$-bar test has better performance when $\mathrm{N}$ and $\mathrm{T}$ are small. They proposed a cross-sectionally demeaned version of both test to be used in the case where the errors in different regressions contain a common time-specific component. One can reject the null hypothesis as given above when the $t_{\text {IPS }}$ statistic is smaller than a critical value from the lower tail of a standard normal distribution.

\subsubsection{The Sargan test of Over identification restrictions}

The Sargan-Hansen test or Sargan's test is a statistical test used for testing over-identifying restrictions in a dynamic panel model. It was proposed by John Denis Sargan in 1958. Lars Peter Hansen re-worked through the derivations and showed that it can be extended to general nonlinear GMM in a time series context. The Sargan test is based on the assumption that model parameters are identified via a priori restrictions on the coefficients, and tests the validity of over-identifying restrictions. The test statistic can be computed from residuals of instrumental variables regression by constructing a quadratic form based on the cross-product of the residuals and exogenous variables. Under the null hypothesis that the over-identifying restrictions are valid, the statistic is asymptotically distributed as a chi-square variable with $(\mathrm{m}-\mathrm{k})$ degrees of freedom $\mathrm{m}$ is the number of instruments and $\mathrm{k}$ is the number of endogenous variables. The null hypothesis of the test is given as; H0: overidentifying restrictions are valid and the null hypothesis is rejected for the significant chi-square statistics. The test is particularly needed for one step GMM estimator. 


\section{Results and Discussion}

\subsection{Countries profile, descriptive statistics and trends of selected economic variables}

The objectives of analyzing both time series and cross sectional data is to identify and describe the underlying structure and phenomenon as depicted by the sequence of observations in the series and to determine the most suitable mathematical model to fit the data series which subsequently use the model to generate forecast values. Accordingly, researcher has shown the trends for selected variables in each country to look some insight growth of each variable in each country.

Economic growth in East Africa has been increasing over the last 16 years. As shown in Fig. 1, All Real GDP growth rate, Real GDP per capita and Real GDP per capita growth trend positively. The highest real GDP growth rate in the region was in 200952.98 in Zimbabwe but after that decreased significantly and the lowest was observed in 2002 in Madagascar. On average the growth rate was 2.344 during the time. The growth rate of real GDP per capita of the region didn't show constant increase or decrease over the time, rather it showed ups and down pattern. The average growth rate of real GDP per capita ranges from minim of 0.092 in 2000 to Maximum of 4.31 in 2009. As depicted in the figure 4.1, the average growth rate of the region was above Zero which shows the region growth rate of real GDP per capita was relatively good as opposed to each countries performance.

The regions Real GDP per capita was very small when compared to other regions of the Continent and world. Ethiopia and Burundi have lowest RGDPPC in the region even though Ethiopia has good growth of Real GDP per capita over time than Burundi. Seychelles is the leading by having greater Real GDP per capita in the region followed by Botswana. As a region it showed good progress over time and the average in the region ranges from $\$ 1451.741$ to $\$ 2112.699$. The following picture shows the average Real GDP per capita of the region over years of 2000-2015.

The population growth rate of the region seems very high. The average population growth rate was more than $2.17 \%$. Seychelles has lowest population growth rate in the region. Uganda has the highest population growth rate of more than $3 \%$ in entire study years.

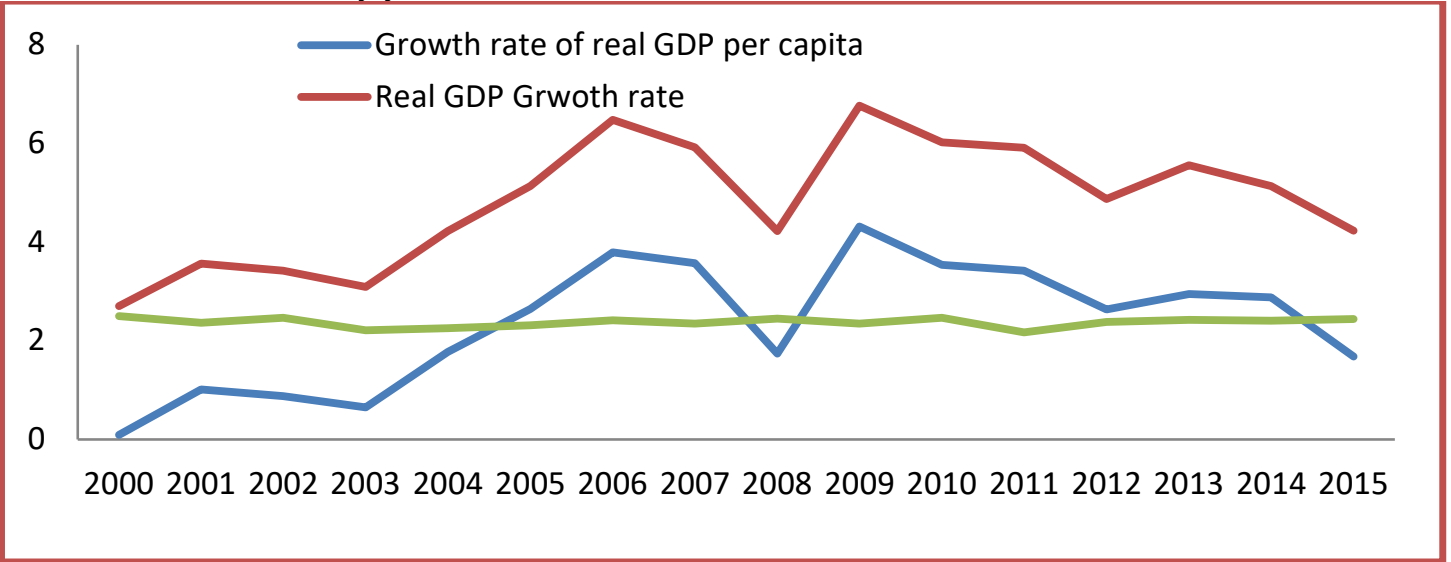

Figure 4.1 - Regional Average growth rate of real GDP per capita, Real GDP growth rate and population growth rate from $2000-2015$

Sources - UN data base and World bank Development indicators (2017)

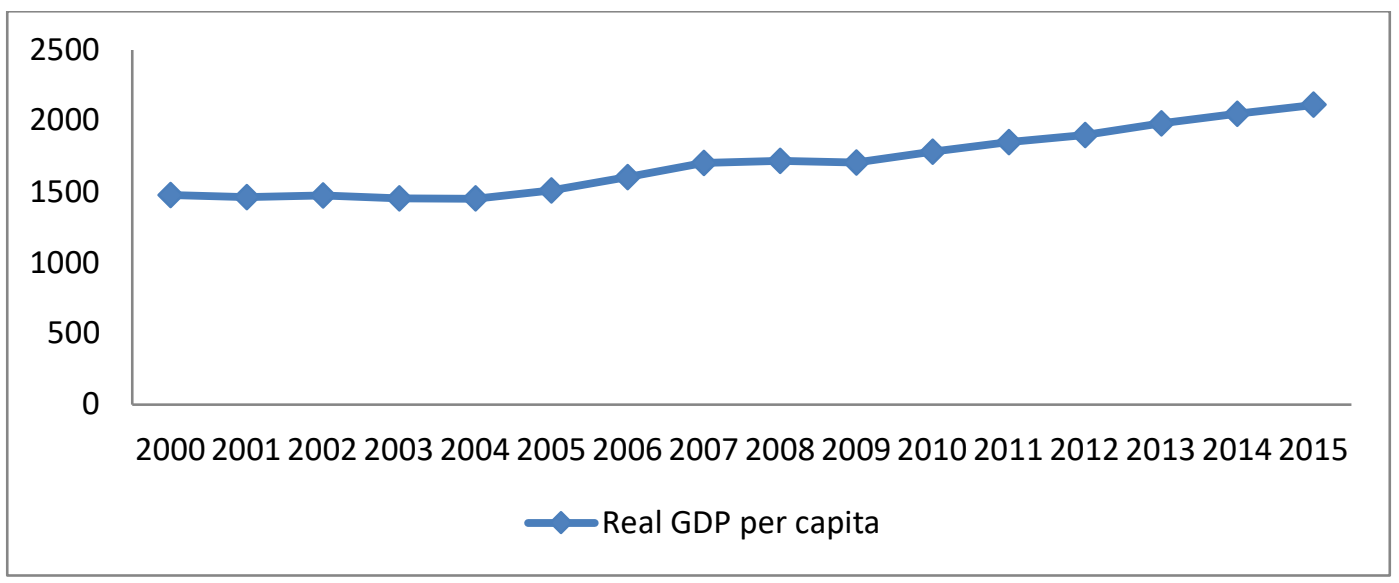

Figure 4.2 - Real GDP per capita of East African Countries from 2000 - 2015

Source-UN data base 


\subsubsection{Telecommunication infrastructures, performances and market}

Africa is undergoing a revolution in information and communications and technology (ICT) that is bringing telecom services within the reach of hundreds of millions of people. The same is true for East African countries. In the 19 countries data collected, the rolls of fixed-line subscribers grew by just 1 million, from 2.2 million lines in 2000 to 3.15 million in 2015. The cellular subscribers increased dramatically from less than 1 million in 2000 to over 250 million in 2015 . The percentage of Internet users increased from less than $2 \%$ in 2000 to over $18 \%$ in 2015. The following graph shows the regional fixed-telephone subscriptions per 100 inhabitants, Mobile-cellular telephone subscriptions per 100 inhabitants and percentage of Individuals using the internet over the study years. There exist wide variations among countries. Mobile cellular subscription grew high but that of fixed line grew with insignificant rate which may not be due to low investment in fixed line network infrastructure rather its demand decrease as technology improved and economic benefit for user seems very low.

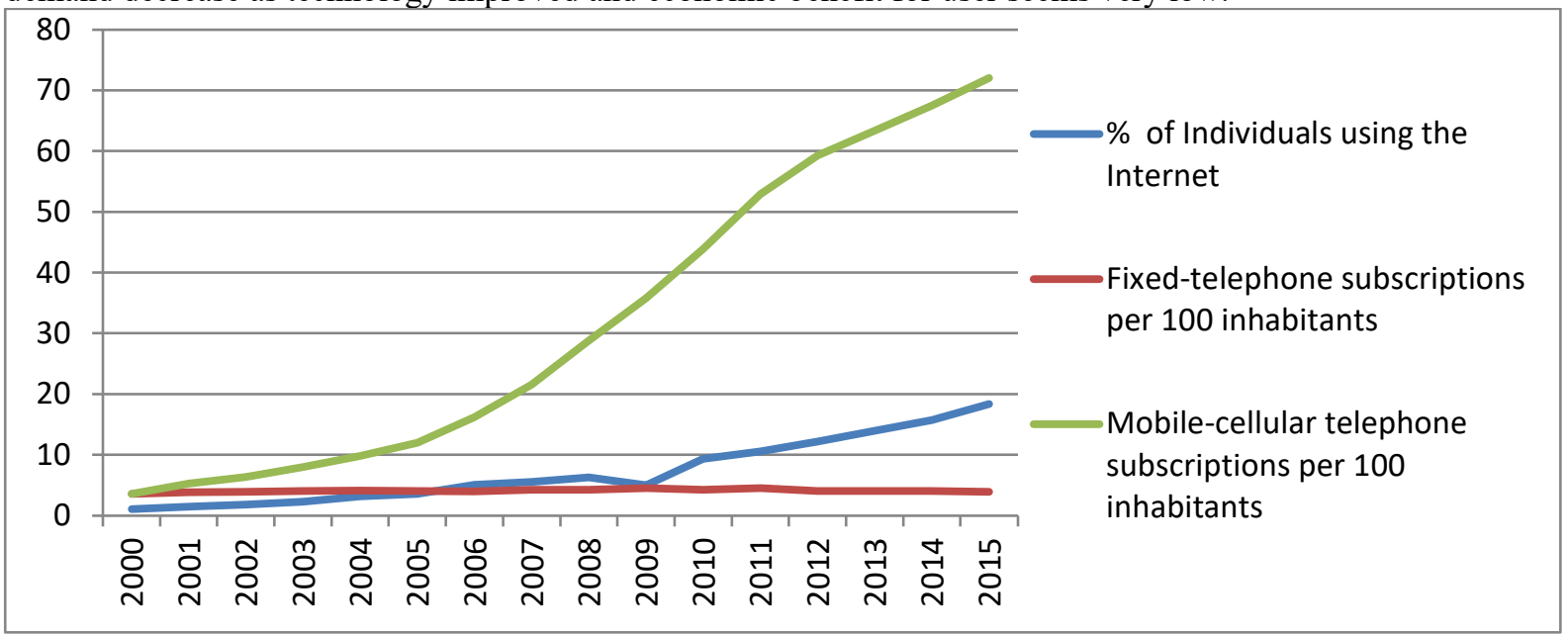

Figure 4.3 - East African Mobile cellular, fixed line and internet user per 100 inhabitants from 2000-2015 Sources - ITU (2017)

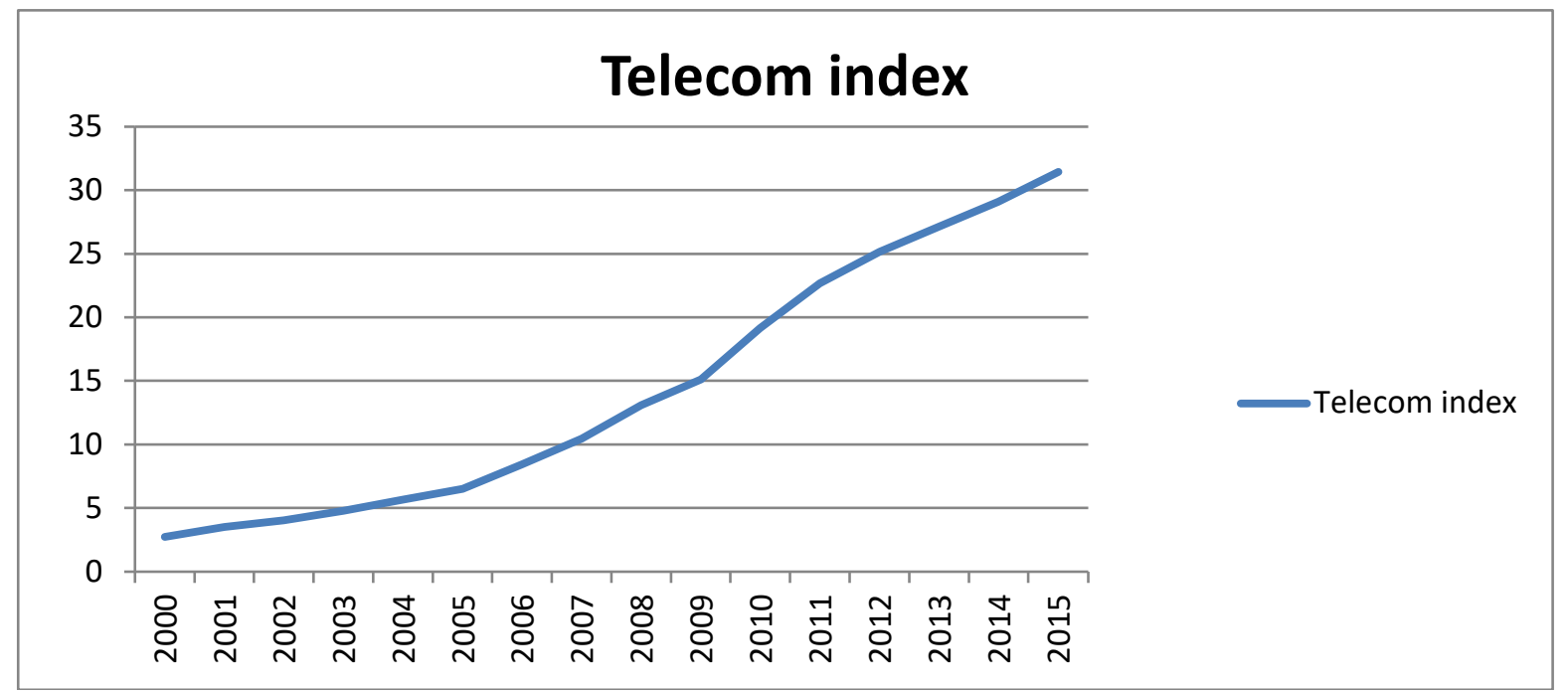

Figure 4.4- The telecom index of East Africa

Own calculation based on ITU data and giving equal weight for mobile cellular, fixed line and internet user per 100 inhabitants in constructing index.

Broadband services got high economic importances recently for banking sectors, finances sectors and other service providers. Data on Mobile broad band is unavailable or very rare if exist in the region as the service is very recent phenomena in the region. Other types of broadband service is Fixed broad band, for which the data exist after 2005. The following graph shows the trend of the service from 2000-2015. 


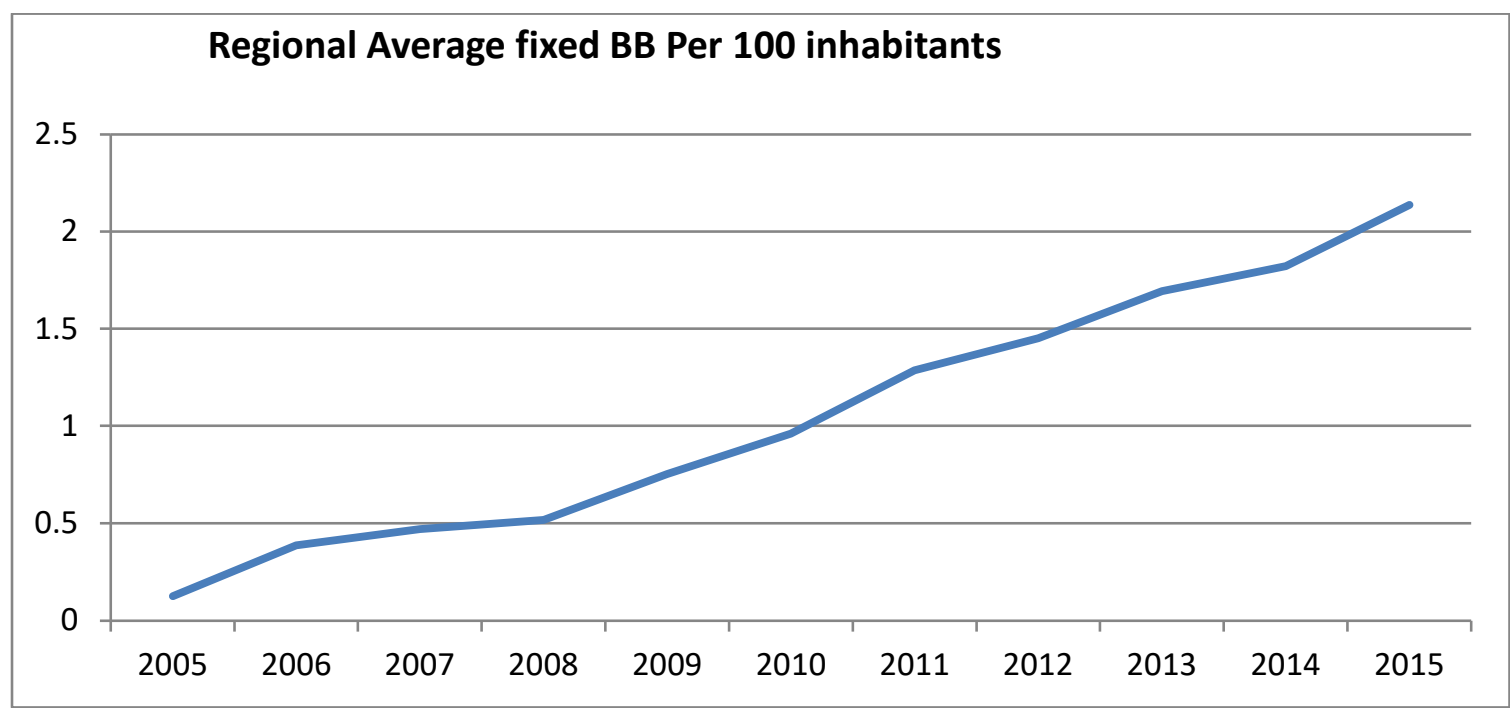

Figure 4.5- East African countries average fixed broadband subscribers per 100 inhabitants from 2000-2015

With regard to telecom market, some of the countries studied have introduced some degree of competition in their telecommunications markets. The researcher divided countries into two panels. The panels of Countries that partially or fully privatized their telecom sector and those keep Monopoly operated by the government. The researcher used World Bank privatization data of 1988-2008 considered as partially, fully or more than 50\% investment in telecom sector investment, the numbers of mobile or fixed line operators in the country - if more than two and legislation (telecommunication policy) that includes investment in Telecom infrastructures, services provisions and distribution considered. By these criteria Kenya is the first country in the region that privatized the telecom sector infrastructure in 1999. Currently Kenya has more than five telecom services operators. Others such as Tanzania, Sudan, Madagascar and Malawi started to privatize their telecom sector after 2000.

Among the countries under study sample about eight countries were considered as those groups of panel that privatized their telecom sector by the above criteria. These countries include Burundi, Kenya, Madagascar, Malawi, Mauritius, Mozambique, Sudan and Tanzania.

The second group is panel of those countries that held their telecom infrastructure investment and telecom service provision monopoly. This panel of countries includes all studied countries that have two and less than two telecom service operators and had no any record of telecommunication infrastructure privatization data of World Bank. These countries are Botswana, Comoros, Djibouti, Eritrea, Ethiopia, Rwanda, Somalia, Uganda, Zambia and Zimbabwe. Some of this group such as Comoros, Djibouti, Eritrea, and Ethiopia retain major restrictions on foreign telecommunication investment in operators.

A. Trends of growth rate of real GDP per capita and telecom index growth rate of those panel of countries that privatized their telecom sector.
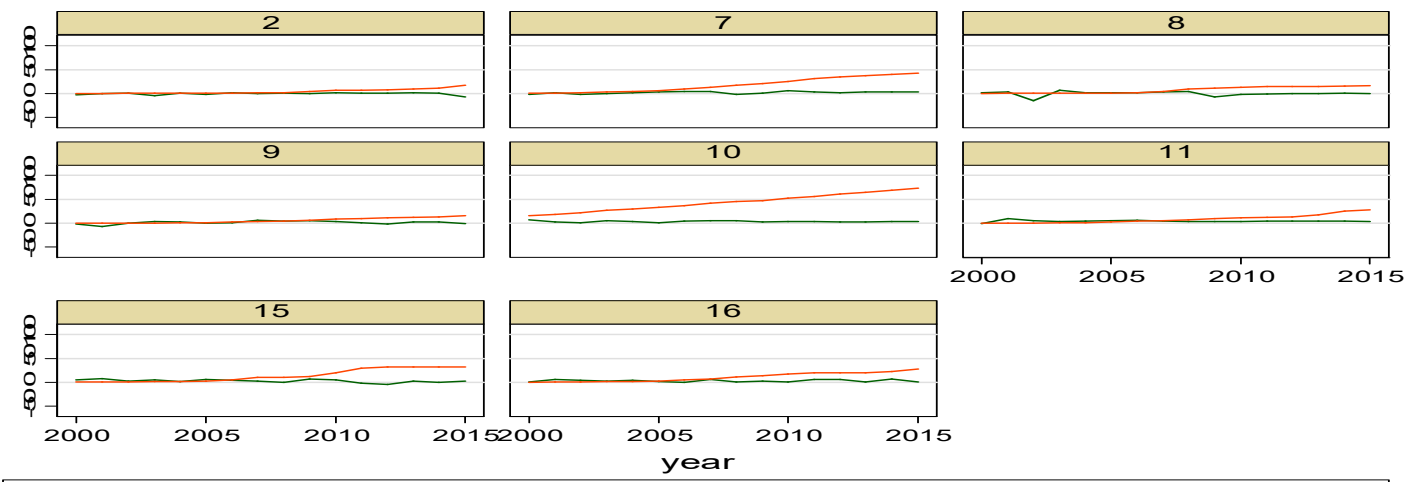

Annual growth rate of the real GDP per capita

Telecom index

Graphs by CountID

Country ID

2. Burundi

7. Kenya

9. Malawi

15.Sudan

8. Madagascar

10. Mauritius

16. Tanzania

Figure 4.6 - The trend of growth rate of real GDP per capita and Telecom index growth rate of East 
African Countries those privatized their telecom sector.

B. Trends of growth rate of real GDP per capita and telecom index growth rate for panel of countries that didn't privatized their telecom sector.
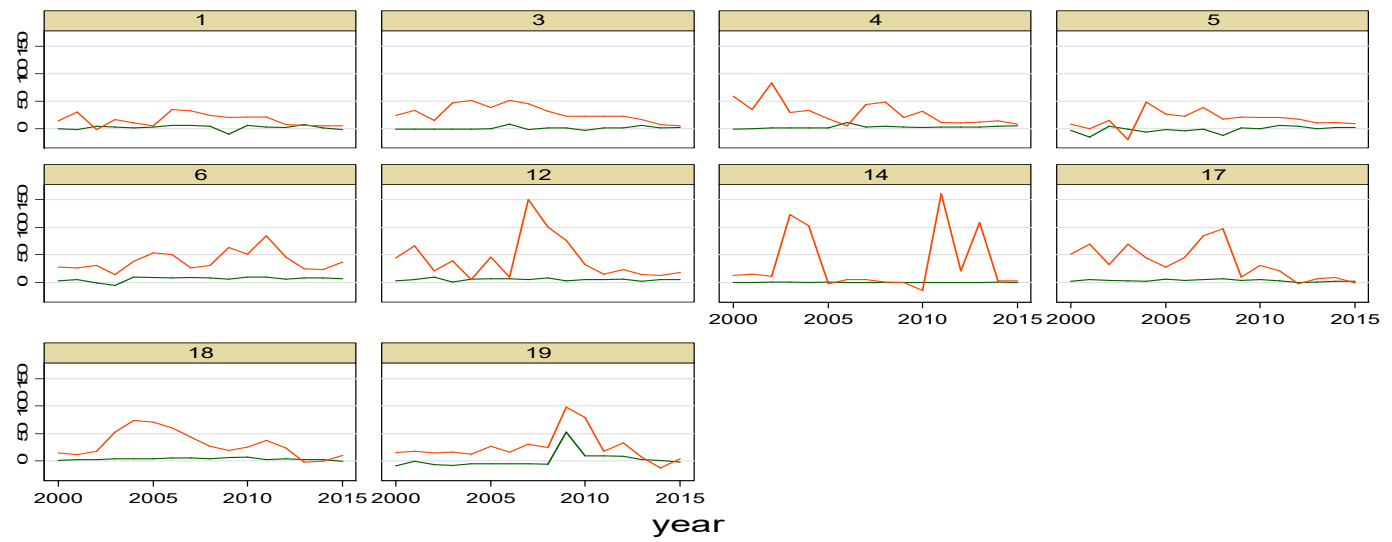

Graphs by CountID

$\longrightarrow$ Growth rate of real GDP per capita $\longrightarrow$ Tel

Country ID
1. Botswana
5. Eritrea
14. Somalia
19. Zimbabwe
3. Comoros
6. Ethiopia
17. Uganda
4. Djibouti
12. Rwanda
18. Zambia

Figure 4.7 - The trend of growth rate of real GDP per capita and Telecom index growth rate of East

African Countries those failed to privatize their telecom sector.

As depicted by two separate graphs above the trends of telecom index growth rate of those countries that privatized their telecom sector were almost upward over time, whereas for those that failed to privatize were unstable over time and their growth of per capita GDP was also insignificant over time.

\subsubsection{Comparisons of telecom growth and other economic variables trends}

The telecom index showed growth over the time, even though the rate of its growth showed a declining trend. This was mainly due to the decline in fixed line subscription rate after mobile network investment got high importances in the region. The trend of economic growth indicators such as real GDP per capital growth rate and real GDP growth rate and telecom index growth rate shows positive relation. They all negatively and highly affected in 2008 which may be due to global economic crisis that affected almost all countries in general. The telecom index has upward trend over entire time because high numbers of Mobile Cellular Subscribers in the region. Real GDP per capita growth rates and real GDP growth rate didn't show significant positive trends over the study years.

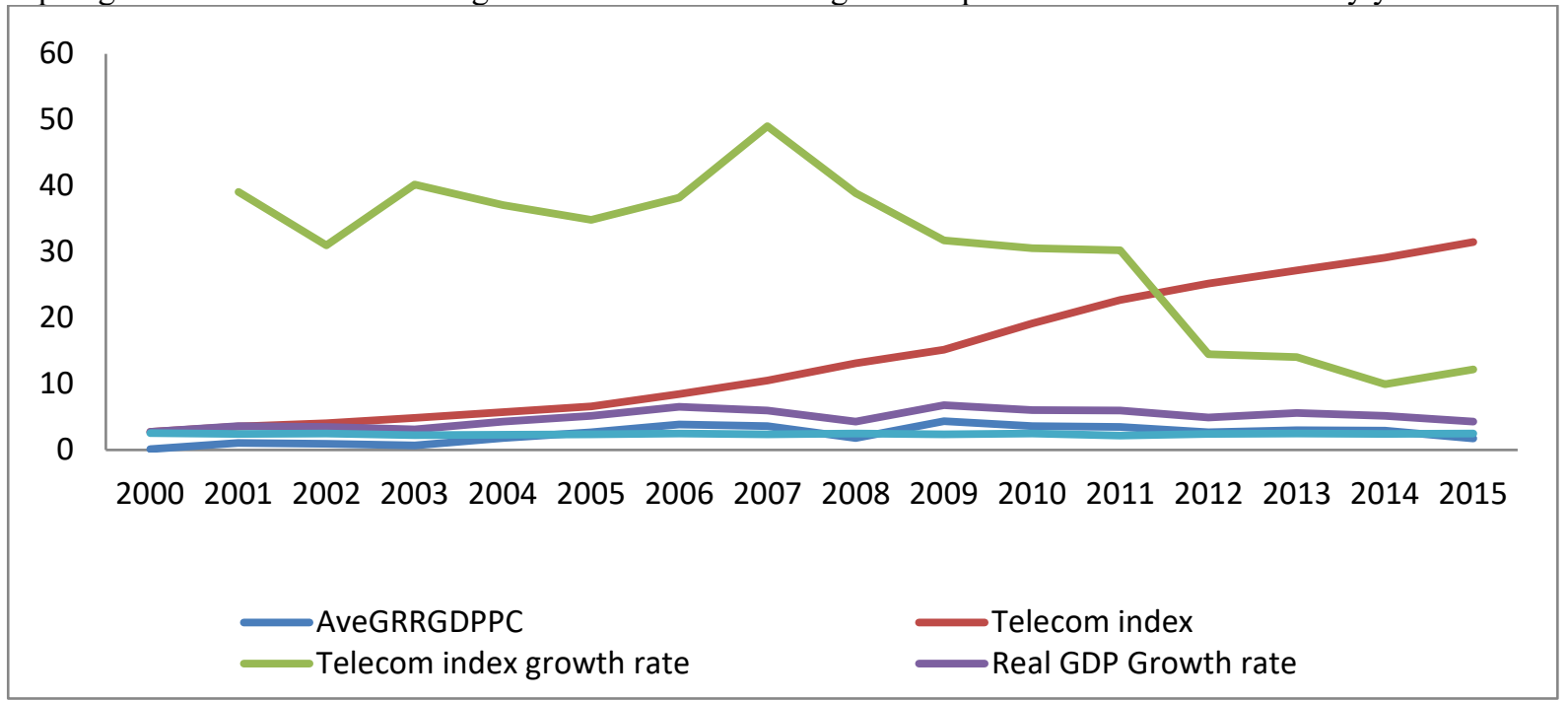

Figure 4.8 - Selected variables trends

General Summary statistics and Correlation coefficients 


\begin{tabular}{|r|rrrrr}
\hline \multicolumn{1}{r}{ summarize } & \multicolumn{7}{l}{} & \\
Variable & Obs & Mean & Std. Dev. & Min & Max \\
\hline CountID & 304 & 10 & 5.486256 & 1 & 19 \\
Year & 304 & 2007.5 & 4.617373 & 2000 & 2015 \\
Growth & 304 & 2.344339 & 4.905435 & -15.26182 & 52.97728 \\
RGDPPC & 304 & 1701.959 & 2990.286 & 132.2335 & 15366.45 \\
Pop & 300 & 2.36972 & .9095885 & -2.628656 & 5.598072 \\
\hline Inf & 284 & 9.753981 & 10.82626 & -5.755335 & 112.6936 \\
Gov & 303 & 2.81954 & 31.77389 & -61.32693 & 445.5622 \\
Inv & 304 & -18.14001 & 419.4336 & -7280.859 & 353.7684 \\
Open & 303 & 1.783206 & 14.40948 & -72.86043 & 88.55934 \\
Tel & 304 & 30.37437 & 27.60036 & -20.09599 & 161.7773
\end{tabular}

Table 4.1- summary statistics

Sources: UN data base (2017), World Bank Development indicators (2017) and ITU (2017)

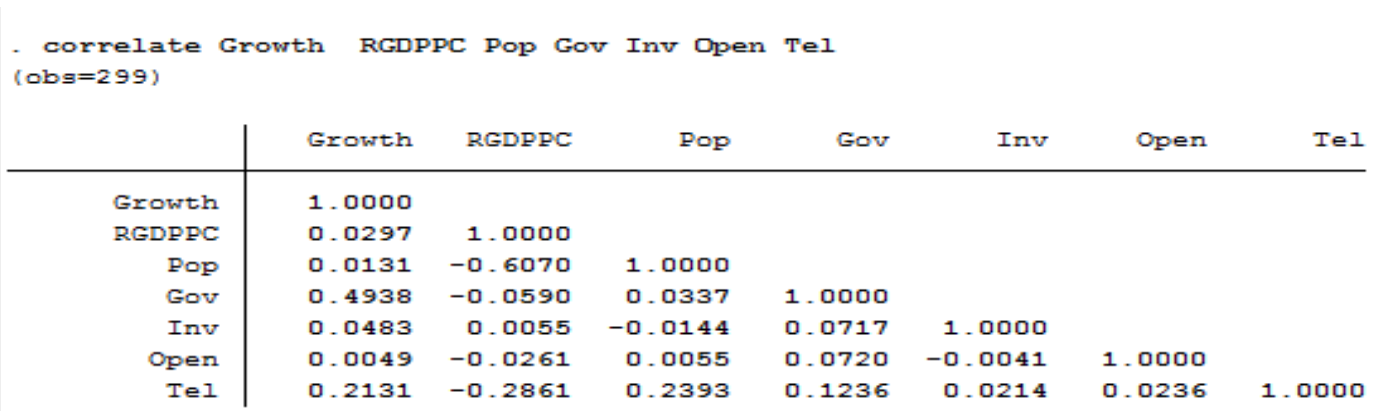

Table 4.2 - Variables correlation coefficients

\subsection{Econometric analysis}

\subsubsection{Panel unit root test result}

Table 4.3, presents the results of the IPS panel unit root test at level indicating that all variables are $I(0)$ not in the constant of the panel unit root regression. These results clearly show that the null hypothesis of a panel unit root in the level of the series can be rejected without any lag. In the absence of a constant plus time trend, again the researcher found that the null hypothesis of having panel unit root is generally rejected in all series at level form Except the RGDPPC. Therefore, He tests for stationarity allowing for a constant plus time trend. It can be conclude that all of the variables are non-stationary with and without time trend specifications at level by applying the IPS test which is also applied for heterogeneous panel to test the series for the presence of a unit root. The results of the panel unit root tests confirm that the variables are non-stationary at level.

Table 4.3: Panel Unit Root Test - Im, Pesaran and Shin (IPS)

\begin{tabular}{|c|c|c|}
\hline Variable at level & Statistics & p-value \\
\hline Growth & -3.7683 & 0.000 \\
\hline RGDPPC $^{*}$ & -2.0356 & 0.0244 \\
\hline Pop & -3.1626 & 0.0045 \\
\hline Gov & -5.1971 & 0.000 \\
\hline Inv & -26.7719 & 0.0000 \\
\hline Open & -4.4519 & 0.000 \\
\hline Tel & -2.4365 & 0.0001 \\
\hline
\end{tabular}

Note: *, Indicates the Variable is not stationary if time trend is not assumed.

The rejection of the null hypothesis of a non-stationarity is at $1 \%$ and $5 \%$, levels of significance.

\subsubsection{Estimation and result}

As already discussed in chapter three the researcher used GMM to estimate the dynamic model specified. GMM applied in the context of semi parametric models, where the parameter of interest is finite-dimensional, whereas the full shape of the distribution function of the data may not be known, and therefore maximum likelihood estimation is not applicable. Once moment conditions which are functions of the model parameters and the data were specified such that their expectation is zero at the true values of the parameters, the GMM method minimizes 
a certain norm of the sample averages of the moment conditions. One step GMM is used here because two step GMM step standard errors were biased downwards and need additional correction procedures even though it is more asymptotically efficient. Both one step and two step GMM estimates are consistent.

The researcher estimates three independent equations separately, to over view the difference of telecom market between panels of those who privatized and failed to privatize the sector. The First equations is contains data of all countries under study sample to see the regional effect of the telecom sector growth on economic growth. The second equation estimate contains the data of countries who privatize their telecom sector and the third equation estimates the data of countries those held their telecom sector to be monopoly.

Table 4.4 indicates the one step GMM estimates of all equations.

\begin{tabular}{|c|c|c|c|c|c|c|c|}
\hline \multirow{9}{*}{ Equation 1} & Growth & Coef. & std.Err & $\mathrm{Z}$ & $\mathrm{P}>|\mathrm{z}|$ & [95\% Conf. & Interval] \\
\hline & Growth L1 & -0.02798 & 0.0470247 & 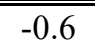 & 0.552 & -0.1201511 & 0.0641823 \\
\hline & Pop & 0.966332 & 0.4943189 & 1.95 & 0.051 & -0.0025148 & 1.93518 \\
\hline & Gov & 0.094949 & 0.0078623 & 12.08 & 0.00 & 0.0795389 & 0.1103583 \\
\hline & Inv & 0.022658 & 0.0078939 & 2.87 & 0.004 & 0.0071863 & 0.0381298 \\
\hline & Open & 0.049731 & 0.0176647 & 2.82 & 0.005 & 0.0151091 & 0.0843536 \\
\hline & Tel & 0.018153 & 0.0088115 & 2.06 & 0.039 & 0.0008833 & 0.0354236 \\
\hline & RGDPPC & -0.00197 & 0.0006624 & -2.97 & 0.003 & -0.003265 & -0.0006682 \\
\hline & cons & 2.664241 & 1.640129 & 1.62 & 0.104 & -0.5503524 & 5.878835 \\
\hline \multirow{9}{*}{ Equation 2} & Growth & & & & & & \\
\hline & L1 & -0.15894 & 0.0880739 & -1.8 & 0.071 & -0.3315638 & 0.0136796 \\
\hline & Pop & 0.679459 & 1.97656 & 0.34 & 0.731 & -3.194527 & 4.553444 \\
\hline & Gov & 0.015175 & 0.0201278 & 0.75 & 0.451 & -0.0242745 & 0.0546249 \\
\hline & Inv & 0.02261 & 0.0108397 & 2.09 & 0.037 & 0.0013648 & 0.0438555 \\
\hline & Open & 0.05265 & 0.0185391 & 2.84 & 0.005 & 0.016314 & 0.0889861 \\
\hline & Tel & 0.026792 & 0.0100473 & 2.67 & 0.008 & 0.0070994 & 0.0464842 \\
\hline & $\begin{array}{c}\text { RGDPPC } \\
\text { L1 }\end{array}$ & -0.00068 & 0.0009939 & -0.68 & 0.495 & -0.0026263 & 0.0012697 \\
\hline & cons & 0.407537 & 5.751454 & 0.07 & 0.944 & -10.86511 & 11.68018 \\
\hline \multirow{8}{*}{ Equation 3} & Growth L1 & 0.033618 & 0.0556605 & 0.6 & 0.546 & -0.0754747 & 0.1427103 \\
\hline & Pop & 1.240721 & 0.5406996 & 2.29 & 0.022 & 0.1809692 & 2.300473 \\
\hline & Gov & 0.111222 & 0.009314 & 11.94 & 0.00 & 0.0929668 & 0.1294768 \\
\hline & Inv & 0.012431 & 0.0105809 & 1.17 & 0.24 & -0.0083075 & 0.0331689 \\
\hline & Open & 0.060474 & 0.0299491 & 2.02 & 0.043 & 0.0017743 & 0.1191726 \\
\hline & Tel & 0.008492 & 0.0114695 & 0.74 & 0.459 & -0.0139883 & 0.0309714 \\
\hline & $\begin{array}{c}\text { RGDPPC } \\
\text { L1 }\end{array}$ & -0.00154 & 0.0007641 & -2.02 & 0.043 & -0.0030408 & -0.0000455 \\
\hline & cons & 2.61874 & 1.908015 & 1.37 & 0.17 & -1.120902 & 6.358381 \\
\hline
\end{tabular}

Table 4.4 - Equations estimation by one step GMM using Stata 13 software

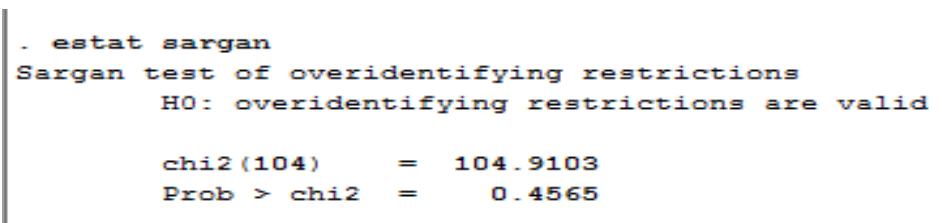

Table 4.5 - The GMM Sargan test of over identifying restrictions for equation 1

IV-GMM regression results in table 4.4 above for whole countries (equation 1) indicated telecommunication infrastructure has a positive effect on economic growth as expected. In particular, the results show that the contribution of the Tel (Telecom Index) to economic growth (real GDP per capital growth rate) is about 0.02 amounts and the coefficient significant $(1 \%$ and $5 \%$ ). It indicates that one percentage increase in telecom index growth raises the real GDP per capita growth by about 0.02 percentage point. Other things remain constants, an increase from 9 to 10 in Mobile cellular subscribers, fixed line subscribers and internet users per 100 inhabitants' people would raise real per capita GDP growth from $2.43 \%$ to $2.46 \%$. The possible reasons could be that the telecommunication services in general and Internet in particular enables business transformations in many sectors and allows the modernization of firms' traditional activities of buying and selling products or offering services to include other dimensions such as online sales or the distribution of products. Internet and Mobile cellular allows the restructuration of business models. According to (Bertschek, 2013) and (Ficawoyi, 2016), the Internet enables 
firms to reorganize and reshape their business processes and to improve their products or services. In other words, it allows firms to innovate, an innovation that is translated into future productivity gains.

In Table 4.4 the coefficient of lagged dependent variable, Growth, is negative but not significant. This confirms the recent findings such as (Ficawoyi, 2016). The coefficient of lagged real GDP Per capita, which measures the effect of past levels of GDP on subsequent growth, is negative and significant at the $1 \%$ and $5 \%$ level. This result supports the convergence hypothesis, which suggests that countries with higher levels of GDP per capita tend to grow at a slower rate.

Gov, the share of government consumption expenditure in GDP, has a significantly positive association with paper growth measurement. One percentage point increase in growth rate of the ration of government expenditure to GDP raises the real GDP per capita growth by about 0.095 percentage point. This indicates that an increase of the government expenditure/GDP ratio by $10 \%$ is associated with an increase of about $1 \%$ in the average annual rate of the real per capita GDP. As opposed to some of previous findings (Datta, 2004) and (Ficawoyi, 2016), the Government role in economy of East African countries are positive and significant which may be due to large government hand in the economy of region and government hold significant investments especially in countries of the region where privatization policy and foreign investments are prohibited.

The coefficient of Inv, the share of fixed investment in GDP, is positive and significant at both $1 \%$ and $5 \%$ significance level. One percentage point increase in growth of investment share of GDP will raise the real GDP per capita growth rate by about 0.023 percentage point. The result confirms almost all previous findings. (Madden, 1998), (Datta, 2004),(Ficawoyi, 2016) and others.

The regression results provide the significant relationship between openness and real GDP per capita growth. The coefficient shows that an increase in outward-oriented economic policies of one percentage point would have an increase of about 0.049 percentage point increase in the average annual growth rate of GDP per capita. The effect of openness confirms the finding of previous studies, i.e. that the role of international trade is beneficial for economic growth in Africa.

The Coefficient of Population growth rate (Pop) is positive and significant at a $1 \%$ level. The positive coefficient of this variable is due to the fact that this panel contains some countries like Mauritius, Seychelles Botswana and Djibouti which have slow growth rate of population in their countries. Such case has been argued by (Enowbi B. M., 2008)

Generally except for the Lagged growth rate of real GDP per capita, all the control variables exhibit coefficients that are statistically significant. Particularly the researchers' interest is the positive and significant value of Telecommunication infrastructure indicator index (Tel) and negative sign of the initial GDP, which substantiates the convergence process in the growth rate.

The Sargan test of overidentifying restrictions indicates that all variables are valid at $1 \%$ and $5 \%$ levels of significance for the GMM method and the test of no autocorrelation is also valid.

The estimation result of second equation which is panel of East African countries that privatized their telecom sector is similar with the whole sample results. The sign of coefficients are almost identical with model one results except coefficient of government expenditure ration of GDP has reduced significantly which may be due to privatization policy have been applied in other sectors as well and government role in countries investment have been reduced. The interesting thing is that the telecom index (Tel) coefficient is more significant than that of all countries result.

In the same way the estimation result of panels of countries that didn't privatized telecom sector is shown above in the table. The sign of Lagged growth is different from other two panels and Telecom index (Tel) has positive coefficient but very small when compared to others. It is also not significant at $1 \%$ and $5 \%$ confidence levels.

Even though we cannot compare the coefficients of these panels directly because of difference in numbers of panels and their economic condition in size and many aspects, the result seems to confirm the previous studies for which telecom has great economic effects in countries where the sector is privatized (Röller, 2001), (Vahagn Jerbashiany, 2011), (Ch.Nondo \& M.Kahsai, 2011) and others.

\section{Conclusion and Recommendation \\ 4.1 Conclusion}

The objective of this study is to investigate the role of telecommunications services to economic growth in East Africa. Telecommunications infrastructure is measured by the growth rates of the telecom index made up of fixed line, internet users and mobile cellular subscribers per 100 inhabitants. The effect of telecommunication infrastructure on economic growth has been explored using a dynamic panel approach and estimated by the GMM method by assuming neoclassical convergence growth theory. To see the effect of telecom market two separate panels have been estimated in addition to the overall regional sample. Both estimation and descriptive statistics of panels of those countries that privatized their telecom and didn't privatize have been undertaken. Overall results suggest that there is a conditional convergence hypothesis which indicates that countries with higher level of GDP 
per capita tend to grow at a slower rate. It also evidences that fixed investment, government expenditure, population growth rate and outward trade policies have a positive effect on economic growth.

More important is that the result shows telecommunication is both statistically significant and positively correlated to regional economic growth in real GDP per capita growth in East Africa. This is consistent with several studies such as (Oliner \& Sichel, 2000), (Datta \& Agarwal, 2004), (Vu, 2011) and (Adonsou, 2016). The overall countries estimation result indicates that a one percentage point increase in telecom services index composed of fixed line, internet user and mobile cellular usage raises per-capita income growth by about 0.02 percentage points. Furthermore, the result indicates one percentage point increase in telecom services index composed of fixed line, internet user and mobile cellular usage raises per-capita income growth by about 0.03 and 0.01 percentage points for those panels of countries that privatized their telecom sector and not privatized respectively.

Generally, there is strong impact of telecommunication services for the economic growth of the region. The Fixed line growth rate is very low when compared to mobile cellular and internet services mainly due to high economic importance of mobile cellular and internet as well as low demand for fixed line because of efficient technology preferences.

\subsection{Recommendations}

$\checkmark$ Understanding these important roles played by telecommunications in national economies, policy measures of facilitating the expansion of telecommunications infrastructures through private and public investment should be pursued vigorously.

$\checkmark$ Countries those held their telecom under government monopoly should privatize their telecom sector in order to construct an efficient telecommunications infrastructure so that they could obtain these high economic values of the telecom services.

$\checkmark$ Further researches needed to examine the role of ICT through telecommunications sector revenues, taxes and employments. This is particularly important to answer the argument that some countries like Ethiopia follow developmental state paradigm in which the government should control investments and operations of key and high revenue generating sector such as telecom, so that it is possible to finance other projects by these sectors' revenues and improve employment. According to this hypothesis the revenues generated by private operators may not be reinvested or used to create more employments which may be more complex when operators are international operators. It is work of the next researchers to analyze and compare the telecommunications contribution through their revenues, taxes and employment creations.

\section{References}

Adeya, C. N. (2001). Information and Communication Technologies in Africa:A Selective Review and Annotated Bibliography of Studies and Projects 1990-2000. Oxford: INASP.

Aghion, P. B. (2005). Competition and innovation:an inverted-U relationship. Q. J. Econ. 120 (2) , 701-728.

Australia, M. S.-r. (2014). The long-run impact of Information and Communication Technology on economic output: The case of Australia.

Bankole, F. O. (2010). Investigating the Impact of ICT investments on Human Development. Electronic Journal on Information Systems in Developing Countries, 48(8) , 2-18.

Blundell, R. G. (1999). Market share, market value and innovation.

Brynjolfsson, E. a. (1996). Productivity, Business Profitability and Consumer Surplus: Three different measures of information technology. MIS Quarterly 20(2) , 121-140.

Canning.D, (. (1999). Does Infrastructure Cause Economic Growth? International evidence for Infrastructure Bottleneck. Harvard Institute for International Development.

Ch.Nondo \& M.Kahsai, 2. (2011). Telecommunications Investment and Economic Development: Evidence from a Panel of Sub-Saharan Africa (SSA). West Virginia University, Research Paper Number 2011-04,Presented at the Southern Regional Science Association, March 2011, , 10-17.

Chavula, H. \&. (2010). ICT Policy Development Process in Africa. International Journals of ICT Research and Development in Africa, 1(3) , 20-42.

Colecchia, A. (2002). ICTinvestmentandeconomicgrowthinthe1990s: Is the United States a unique case? A comparative study of nine OECD countries. Review of Economic Dynamics .

Alessandra,\&Schreyer,Paul.(2002).ICTinvestmentandeconomicgrowthinthe1990s:Is the United States auniquecase? Acomparative study of nine OECD countries. . Review of Economic Dynamics, 5(2), , 400-430.

Dedrick J. and Kraemer K.L, 1. (1994). Payoffs from Investment in Information Technology: Lessons from The ASIA-PACIFIC Region. World Development 22 (12) , 1920-1928.

Dedrick J., K. K. (2001). IT-Led Development in Singapore: From Winchester Island to Inteligent Island. working paper \#ITR-123, Center for Research on Information Technology and Organizations, Graduate school of Management, University of California, Irvine .

Dewan, S. (2000). Information technology and productivity:evidence from country-leveldata. Management 
Science, 46(4), , 545-560.

Ding, L. a. (2004). Telecommunication Policy Research Conference . Telecommunication Policy Research Conference. Washington. DC.

Hana, N. K. (2003). Why National Strategies are needed for ICT-enabled Development. ISG Staff Working Papers no.3 June 2003 .

Hitt, L. a. (1996). Productivity, Business Profitability and Consumer Surplus: Three different measures of information technology.

Jalava, J. P. (2002). EconomicgrowthintheNewEconomy:evidence from advanced economies. .

Jorgenson D. W., a. S. (2000). Raising the Speed Limit: U.S. Economic Growth in the Information Age. Brookings Papers on Economic Activity 2000 , 130-189.

Jorgenson, D. (2008). AretrospectivelookattheU.S.productivitygrowthresurgence. . The Journal of Economic Perspectives .

Joseph K.J., 2. (2002). Growth of ICT and ICT for development - Realities of the myths of the Indian experience. Discussion paper no. 2002/78. UNU/WIDER, Helsinki .

Kaiser. U, (. (2003). Strategic Complementarities between Different Types of ICT-expenditures. Centre for Economic and Business Research, Discussion Paper, 2-15.

Karagol, B. \&. (2012). Macroeconomic Effects of Information and Communication Technologies in Turkey and Other OECD Member Countries. Science and Technology Policies Research centre, TELPOL Working Paper Series, STPS-WP-12/05.pp. , 5-40.

Kraemer K. and Tallon P, 1. (1999). The Impact of Technology on Ireland's Economic Growth and Development: Lessons for Developing. Center for Research on Information Technology and Organizations, Graduate School of Management, University of California, Irvine.

Kraemer, K (2000). Informationtechnologyandproductivity:evidencefromcountry-leveldata. Management Science, $46(4)$, , 548-560

Michael. E., (. (2008). The Role of Telecommunication Infrastructure in the Regional Economic Growth of Africa. MPRA Paper No. 12431, 2-17.

Miles, P. (2001). Globalisation- Economic Growth and Development Indicators.

Nandi.B, \&. C. (2003). Privatization, telecommunications and growth in selected Asian countries: An econometric analysis. Communications and strategies, (52) , 30-46.

NNgwenyama, O. A.-B. (2006). Is there a Relationship Between ICT, Health, Education and Development?An Empirical Analysis of Five West African Countries from 1997-2003,. Electronic Journal on Information Systems in Developing Countries 23(5): , 2-10.

Norton, S. W. (1992). Transaction costs, telecommunications, and the microeconomics of.

Norton, S. W. (1992). Transaction costs, telecommunications, and the microeconomics of.

Norton, S. W. (1992). Transaction costs, telecommunications, and the microeconomics of macroeconomic growth. Economic Development and Cultural Change, 41(1), 80-96.

Okogun, O. A. (2012). Economic Value of ICT Investment in Nigeria: Is it commensurate? . International Journal of Economics and Management Sciences Vol. 1, No. 10, 2012, 20-28.

Oliner, S. a. (2000). Federal Reserve Board working paper. The Resurgence of Growth in the Late 1990s: Is Information Technology the Story?

P., K. K. (1999). The Impact of Technology on Ireland's Economic Growth and Development: Lessons for Developing. Center for Research on Information Technology and Organizations, Graduate School of .

Parker, E. G. (1993). Telecommunicationsinfrastructureinvestmentandeconomicdevelopment. Telecommunications Policy, 17(6) , 415-427.

Pohjola, M. J. (2002). EconomicgrowthintheNewEconomy:evidencefromadvancedeconomies. Jalava,J.,\&Pohjola,M.(2002).EconomicgrowthintheNewEconomy:evidencefromadvancedeconomies. Information Economics and Policy, 14(2), , 189-208.

Rezaian, B. (. (2007). Rezaian, B. (2007). Integrating ICTs in African DevelopmenRezaian, B. (2007). Integrating ICTs in African Development: Challenges and Opportunities in Sub-Saharan Africa .

Shahiduzzaman, M. (2014). Information technology and its changing roles to economic growth and productivity in Australia. Telecommunications Policy,38, 125-134.

Solow, R. (1956). A contribution to the theory of economic growth. Quarterly journal of Economics, 70(1) , 65 94.

van de Klundert, T. S. (1997). Growth, competition and welfare. Scand. J. Econ.99 (1) , 99-118.

Vives, X. 2. (2008). Innovation and competitive pressure. J. Ind. Econ. 56 (3) , 419-469.

Wong, P.-K. (2002). ICT Production and Diffusion in Asia: Digital Dividends or Digital Divide? Information Economics and Policy 14: , 167-186.

World Bank. (2002, April). http://info.worldbank.org. Retrieved from http://info.worldbank.org/ict/ICT_ssp.html 